\title{
Mixed oligopoly and environmental policy
}

\author{
Juan Carlos Bárcena-Ruiz* and María Begoña Garzón \\ Departamento de Fundamentos del Análisis Económico
}

\begin{abstract}
The literature on mixed oligopoly does not consider the role that the environmental policy of the government plays on the decision whether to privatize public firms. Assuming that there are one public firm and $n$ private firms and that the government chooses an environmental standard we show that, when the number of private firms is low enough, the public firm is privatized if it is inefficient enough. When the number of private firms is high enough, the government always privatizes the public firm. We also show that the range of values of the parameters for which the government privatizes the public firm is greater than when environmental policy is not considered.
\end{abstract}

Key words: environmental standard, mixed oligopoly, privatization.

JEL classification: L33, Q28.

** Corresponding author: Juan Carlos Bárcena-Ruiz. Departamento de Fundamentos del Análisis Económico, Universidad del País Vasco. Avenida Lehendakari Aguirre, 83; 48015 Bilbao, Spain. Phone: (34) 9460138 15; Fax: (34) 9460137 74. E-mail: jepbaruj@bs.ehu.es 


\section{Introduction}

One of the questions analyzed by the literature on mixed oligopoly is the decision by the government to privatize a public firm (see De Fraja and Delbono, 1989, 1990; Barros, 1995; Matsumura, 1998). This literature does not assume explicitly that firms pollute the environment and, thus, the environmental policy of the government is not taken into account when deciding whether to privatize the public firm or not. On the other hand, the literature on the environment analyzes the environmental policy of the government but does not consider that there are public firms competing with private firms in the product market (see Barret, 1994; Markusen et al, 1995, 1997; Ulph, 1996). The purpose of this paper is to analyze the decision by the government to privatize a public firm when it cares about the environment by choosing an environmental standard to control pollution.

The literature on mixed oligopoly (see De Fraja and Delbono, 1989, 1990) shows that, when the cost function is convex, the government privatizes the public firm if the number of private firms is high enough; when the number of private firms is low enough, the government always prefers a mixed oligopoly. On the other hand, when firms have a constant marginal cost of production and the public firm is less efficient than private firms, ${ }^{1}$ it can be shown that for any number of private firms, the government privatizes the public firm if its inefficiency is high enough; this inefficiency depends on the marginal cost of the public firm, on the number of private firms and on market size. ${ }^{2}$ We consider this last case as a benchmark case.

\footnotetext{
1 This assumption is usually employed in the mixed oligopoly literature to avoid a trivial solution. If the public firm is more or equally efficient than the private firms, the public firm would produce a quantity such that the market price equals its marginal cost, resulting in a public monopoly (see Pal, 1998; Estrin and de Meza, 1995). Empirical evidence shows both the superior efficiency of private firms relative to comparable public firms (Mueller, 1989; Vining and Boardman, 1992), and the improvement in efficiency after privatization (Kikery et al. 1992; Megginson et al. 1994).
}

2 We show this result in Lemmas 4 and 5. 
In order to take into account that the government fixes an environmental standard and decides whether to privatize the public firm or not, we extend the Ulph's (1996) model with the following assumptions. First, there are $n$ private firms and one public firm that pollute the environment. Second, the public firm is less efficient than the private firms. Each unit of the good produced, in both the private and public firms, causes one unit of pollutant. In order to control environmental damage the government announces an upper limit on emissions (an environmental standard). The producers have to abate pollution emissions, which involves a positive cost, to comply with this upper limit.

In this framework, the social welfare function comprises the consumer surplus, the producer surplus and the environmental damage. Given that the public firm maximizes social welfare, the output of industry in the mixed oligopoly is greater than in the private oligopoly. Therefore, the consumer surplus is greater and the producer surplus is lower in the mixed oligopoly than in the private oligopoly. When $n$ is high, the environmental damage is greater in the private oligopoly than in the mixed oligopoly; when $n$ is low, the environmental damage may be greater or lower.

Taking into account the above results we show that when the number of private firms is low $(n \in\{1,2\})$, the government privatizes the public firm if the latter is inefficient enough; this inefficiency depends on the marginal cost of the public firm, on market size and on the valuation of the environment by the government. When the number of private firms is high $(n \geq 3)$ the government always privatizes the public firm.

In this paper we also show that when the government sets an environmental standard the range of values of the parameters for which the government privatizes the public firm is greater than in the benchmark case. In fact, when $n$ is high, the government always privatizes the public firm; in the benchmark case, the government only privatizes it when its inefficiency is high enough. 
The paper is organized as follows. Section 2 presents the model. Section 3 analyzes whether the government privatizes the public firm when it chooses an environmental standard and there is one private firm. Section 4 analyzes the benchmark case and compares the results obtained in this case with those obtained in the preceding section. Section 5 extends the model by assuming $n$ private firms. Conclusions are drawn in section 6 .

\section{The Model}

We consider a single industry made up of two firms producing a homogeneous good: one firm is publicly owned, 0 , and the other firm is private, 1 . If the public firm is privatized there are two private firms competing in the market. The inverse demand function for the homogeneous good is:

$$
p=A-q_{0}-q_{1}
$$

where $p$ is the price of the good and $q_{i}$ is the amount of the good produced by firm $i, i=0,1$.

We assume that the private firm has a constant marginal cost of production which is normalized to zero. We also assume that the public firm is less efficient than the private firm; therefore, if the public firm is privatized there is an improvement in efficiency. The marginal cost of production of the public firm is constant and equal to $c$, where $0<c<\bar{c}=A / 4 .{ }^{3}$

We consider that each unit of the good produced, in both the private and public firms, causes one unit of pollutant. ${ }^{4}$ The government has the environmental standard as a decision variable to control pollution. Thus, to control environmental damage the government

\footnotetext{
${ }^{3}$ In order to eliminate irrelevant cases we assume, without loss of generality, that $c<\bar{c}$.
} 
announces an upper limit on emissions, $e$. The environmental standard is identical for the two firms since they produce a homogeneous good with the same polluting technology. The two producers have technology available for abating this pollutant, and that technology is the same for both firms. If the government sets the environmental standard $e$ and producer $i$ chooses the output level $q_{i}$, producer $i$ has to abate emissions by $\left(q_{i}-e\right)$ and thus the total cost of pollution abatement for firm $i$ is: $C A_{i}=\left(q_{i}-e\right)^{2} / 2, i=0,1 .^{5}$

When the government sets an environmental standard, $e$, the profit function of firm $i$ is:

$$
\pi_{i}=\left(A-q_{i}-q_{j}-c_{i}\right) q_{i}-\frac{1}{2}\left(q_{i}-e\right)^{2}, i, j=0,1 ; i \neq j, c_{1}=0, c_{0}=c
$$

The social welfare function considered by the government comprises the consumer surplus, $C S$, the producers surplus, $P S$, and the environmental damage caused by the production process, $E D$. Thus, the social welfare function can be expressed as:

$$
W=C S+P S-E D \text {. }
$$

We use a quadratic functional form to measure the environmental damage generated in the country by the production activity of the two firms: $E D=d(e+e)^{2} / 2, d>1.6$ The parameter $d$ measures the valuation of the environment by the government and can be interpreted as the

\footnotetext{
4 We extend the Ulph's (1996) model by considering one public firm and one private firm instead of two private firms.

5 The abatement cost function considered in this paper is a particular case of the more general function: $C A_{i}$ $=k\left(q_{i}-e\right)^{2} / 2$. For the sake of simplicity, we assume in the model that $k=1$ but it can be shown that the results of this paper are robust to changes in parameter $k$.

6 We assume that $d>1$ to assure that the pollution abatement level is positive. This type of damage function is commonly used in literature and assumes that the environmental damage is a convex function of the total pollution level and that this damage is exogenous for consumers. See, for example, Falk and Mendelsohn (1993), van der Ploeg and Zeeuw (1992) and Ulph (1996).
} 
willingness to pay to decrease environmental damage by one unit. As usual, the consumer surplus is: $C S=\left(q_{0}+q_{1}\right)^{2} / 2$, and the producer surplus is: $P S=\pi_{0}+\pi_{1}$.

The timing of the game is the following. In the first stage, the government decides whether to privatize the public firm. In the second stage, the government chooses the environmental standard. ${ }^{7}$ Lastly, in the third stage, each firm chooses its output level. We solve the game by backward induction from the last stage of the game to obtain a subgame perfect Nash equilibrium.

\section{Environmental standard and the decision whether to privatize}

In this section we analyze the decision by the government to privatize the public firm when it sets an environmental standard to control pollution. Given that the public firm can be privatized, there are two possible cases in the first stage: a mixed duopoly (denoted by superscript $M$ ) and a private duopoly (denoted by superscript $P$ ).

\subsection{Mixed duopoly}

In the third stage of the game, for a given environmental standard, the private firm chooses the output level, $q_{1}$, that maximizes its profit function; the public firm chooses the output level, $q_{0}$, that maximizes the social welfare function. Solving these problems simultaneously, we get:

$$
q_{0}=\frac{1}{5}(2 A-3 c+2 e), q_{1}=\frac{1}{5}(A+c+e)
$$

\footnotetext{
${ }^{7}$ Given that the emission abatement cost is a convex function, the emission level of each firm is exactly the maximum permitted by the government; that is, the environmental standard $e$.
} 
It is easy to see that $\partial q_{0} / \partial e=2 / 5$ and $\partial q_{1} / \partial e=1 / 5$. Thus, all else being equal, an increase of the environmental standard raises the equilibrium output of both firms, but the output of the public firm rises more than that of the private firm, because the former is more aggressive in the product market than the latter since its objective function is social welfare and, thus, takes consumer surplus into account.

In the second stage of the game, the government chooses the environmental standard that maximizes social welfare. Solving this problem we obtain the following result.

Lemma 1. In the mixed duopoly, in equilibrium, the environmental standard, the output levels of the firms, the profit of the firms, the environmental damage, the consumer surplus and social welfare are, respectively:

$$
\begin{aligned}
& e^{M}=\frac{16 A-9 c}{34+100 d}, q_{0}^{M}=\frac{2(5 A(1+2 d)-3 c(2+5 d))}{17+50 d}, q_{1}^{M}=\frac{5(2 A(1+2 d)+c(1+4 d))}{2(17+50 d)} \\
& \pi_{0}^{M}=\frac{\left(16 A^{2}\left(9+100 d+100 d^{2}\right)-96 A c\left(7+45 d+50 d^{2}\right)+45 c^{2}\left(11+64 d+80 d^{2}\right)\right)}{8(17+50 d)^{2}} \\
& \pi_{1}^{M}=\frac{\left(2 A^{2}\left(11+300 d+300 d^{2}\right)+6 A c\left(49+150 d+200 d^{2}\right)-3 c^{2}\left(1-100 d-200 d^{2}\right)\right)}{4(17+50 d)^{2}} \\
& E D^{M}=\frac{2 d(16 A-9 c)^{2}}{4(17+50 d)^{2}}, C S^{M}=\frac{(30 A(1+2 d)-c(19+40 d))^{2}}{8(17+50 d)^{2}} \\
& W^{M}=\frac{\left(32 A^{2}(1+2 d)-36 A c(1+2 d)+c^{2}(25+64 d)\right)}{4(17+50 d)}
\end{aligned}
$$

All else being equal, the government sets a higher standard the lower the marginal cost of the public firm $\left(\partial e^{M / \partial c<0}\right)$ and the lower the valuation of the environment by the government $\left(\partial e^{M / \partial d<0) . ~ O n ~ t h e ~ o t h e r ~ h a n d, ~ s o c i a l ~ w e l f a r e ~ d e c r e a s e s ~ w i t h ~} d\left(\partial W^{M / \partial d<0)}\right.\right.$ and with $c$

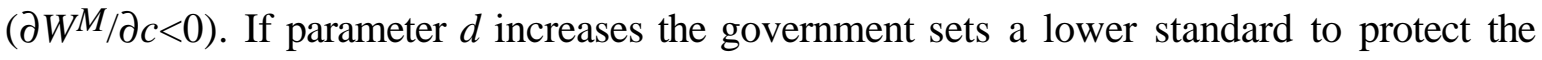


environment; this reduces social welfare given that the total output of industry and the consumer surplus decrease. If parameter $c$ increases, the inefficiency of the public firm is greater, which implies that the output of industry and the consumer surplus decrease. As a result, the environmental damage (and, thus, the environmental standard) must be lowered to offset this reduction in the consumer surplus. Given the strong weight of the consumer surplus in social welfare, social welfare decreases with parameter $c$.

\subsection{Private duopoly}

In the third stage of the game, for a given environmental standard, firm $i$ chooses the output level, $q_{i}$, that maximizes its profit function. Solving these problems simultaneously, we get:

$$
q_{i}=\frac{A+e}{4}, i=0,1
$$

In the second stage of the game, the government chooses the environmental standard that maximizes social welfare. Solving this problem we obtain the following result.

Lemma 2. In the private duopoly, in equilibrium, the environmental standard, the output level of the firms, the profit of the firms, the environmental damage, the consumer surplus and the social welfare are, respectively:

$$
\begin{aligned}
& e^{P}=\frac{5 A}{11+32 d}, q_{1}^{P}=q_{0}^{P}=\frac{4 A(1+2 d)}{11+32 d}, \pi_{0}^{P}=\pi_{1}^{P}=\frac{A^{2}\left(23+192 d+192 d^{2}\right)}{2(11+32 d)^{2}}, \\
& E D^{P}=\frac{50 d A^{2}}{(11+32 d)^{2}}, C S^{P}=\frac{32 A^{2}(1+2 d)^{2}}{(11+32 d)^{2}}, W^{P}=\frac{5 A^{2}(1+2 d)}{11+32 d} .
\end{aligned}
$$


All else being equal, social welfare decreases with $d\left(\partial W^{P} / \partial d<0\right)$ and the government sets a higher standard the lower the willingness to pay to decrease the environmental damage by one unit $\left(\partial e^{P} / \partial d<0\right)$.

\subsection{Comparison of the results and the decision whether to privatize}

In this section we have to solve stage one, i. e. we have to analyze whether the government privatizes the public firm or not. By comparing lemmas 1 and 2 we obtain the following result, which is useful to study the decision by the government on whether to privatize.

Lemma 3. In equilibrium: $q_{0}{ }^{M}>q_{0}^{P}=q_{1}^{P}>q_{1}{ }^{M}, q_{0}{ }^{M}+q_{1}{ }^{M}>q_{0}^{P}+q_{1} P, C^{M}>C^{P}$ and $P S^{P}>P S^{M}$.

By comparing the equilibrium output levels obtained in the mixed and private duopolies, we get that $q_{0}{ }^{M}>q_{0} P=q_{1} P>q_{1}{ }^{M}$ and $q_{0}{ }^{M}+q_{1}{ }^{M}>q_{0}{ }^{P}+q_{0} P$. This is the usual result obtained in the literature on mixed duopoly (see De Fraja and Delbono, 1989, 1990). Given that the public firm chooses the output level that maximizes social welfare (and, thus, takes consumer surplus into account), it is more aggressive in the product market than private firms. As a result, the public firm produces the higher output level, the private firm in the mixed duopoly produces the lower output level, and the output of industry is greater in the mixed duopoly. This result is obtained although the abatement cost is a convex function, which implies that the total cost of abating pollution paid by the public firm is higher (it is easy to see that $q_{0} M_{-}$

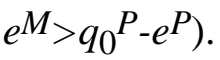


In equilibrium, the consumer surplus can be written as: $C S^{i}=\frac{1}{2}\left(q_{0}^{i}+q_{1}^{i}\right)^{2}, i=M, P$. Thus, given that the greater industry output is obtained in the mixed duopoly, the greater consumer surplus is also obtained in this case.

As usual in mixed oligopoly literature, the profit of industry is greater in the private duopoly than in the mixed duopoly $\left(P S^{P}>P S^{M}\right)$. This is explained by three effects. First, the public firm is more aggressive in the product market than private firms, implying that competition in the product market is greater in the mixed duopoly. Second, given that the output of the public firm is higher, its abatement cost is also higher. Third, the marginal cost of the public firm is greater than that of the private firm.

Before analyzing the decision whether to privatize the environmental standards chosen by the government in the mixed and private duopolies must be compared.

Proposition 1. In equilibrium, the environmental standard and environmental damage are lower in the mixed duopoly than in the private duopoly if and only if parameter $c$ is greater than $c_{\alpha}$, where: $c_{\alpha}=\frac{2 A(1+2 d)}{3(11+32 d)}$, and $0<c_{\alpha}<\bar{c}$.

The standard fixed by the government in the private duopoly, $e^{P}$, does not depend on the marginal cost of the public firm, $c$; however, $e^{M}$ depends inversely on parameter $c$. Thus, if $c$ is low enough we have that $e^{M}>e^{P}$; however, if $c$ is high enough we have that $e^{M}<e^{P}$. Therefore, only if the public firm is inefficient enough $\left(c>c_{\alpha}\right)$ the standard set in the private duopoly is greater than that set in the mixed duopoly. 
As we have seen, $q_{0}{ }^{M}+q_{1} M$ is greater than $q_{0}{ }+q_{1} P$; therefore, intuition suggests that the environmental standard in the mixed duopoly should be lower than in the private duopoly. But, as proposition 1 shows, $e^{M}$ can be greater or lower than $e^{P}$.

If the marginal cost of the public firm, $c$, is low enough $(c<c<)$, the difference between the output level of the public firm and that of private firms is great since the inefficiency of the public firm is low enough; therefore, $C S^{M}$ is greater than $C S^{P}$. Given the great weight of the consumer surplus in social welfare, $C S^{M}+P S^{M}$ is also greater than $C S^{P}+P S^{P}$. As a result, when parameter $c$ is low enough the government sets a higher standard in the mixed duopoly $\left(e^{M>} e^{P}\right)$ since the greater sum of consumer and producer surplus permits greater environmental damage.

If parameter $c$ is high enough $\left(c>c_{\alpha}\right)$, the difference between the output level of the public firm and that of private firms is low since the inefficiency of the public firm is high enough; therefore, the difference between $C S^{M}$ and $C S^{P}$ is low. On the other hand, as $c$ is high enough, $P S^{P}$ is sufficiently greater than $P S^{M}$. As a result, $C S^{P}+P S^{P}$ is greater than $C S^{M}+P S^{M}$ and the government sets a higher standard in the private duopoly $\left(e^{M}<e^{P}\right)$ since the greater sum of consumer and producer surplus permits greater environmental damage.

In equilibrium, environmental damage can be expressed as: $2 d\left(e^{i}\right)^{2}, i=M, P$. Therefore, environmental damage is greater when the government sets a higher standard: $E D^{M}>E D^{P}$ if and only if $e^{M}>e^{P}$.

In proposition 1 we have compared the environmental standard chosen by the government in the two market structures considered. However, it remains to be studied whether the government privatizes the public firm or not. 
Proposition 2. In equilibrium, the government privatizes the public firm when $c_{\beta} \leq c<\bar{c}$; when $0<c<c_{\beta}$ the government prefers a mixed duopoly, where: $c_{\beta}=\frac{2 A(1+2 d)\left(99+288 d-4 \sqrt{3} \sqrt{187+1094 d+1600 d^{2}}\right)}{275+1504 d+2048 d^{2}}, 0<c_{\beta}<c_{\alpha}<\bar{c} .8$

This proposition shows that if parameter $c$ is high enough $\left(c_{\beta} \leq c<\bar{c}\right)$, the government privatizes the public firm. However, if parameter $c$ is low enough $\left(0<c<c_{\beta}\right)$, the government prefers a mixed duopoly. We can identify three zones: zone I $\left(0<c<c_{\beta}\right)$, zone II $\left(c_{\beta} \leq c<c_{\alpha}\right)$, and zone III $\left(c_{\alpha} \leq c<\bar{c}\right)$. In these three zones, as we have seen in lemma 3 , $C S^{M}$ is greater than $C S^{P}$ but $P S^{M}$ is lower than $P S^{P}$; however, proposition 1 shows that environmental damage in the mixed duopoly can be greater or lower than in the private duopoly $\left(E D^{M}<E D^{P}\right.$ if and only if $\left.c>c_{\alpha}\right)$.

In order to explain the decision taken by the government it must be noted that if the public firm is privatized it changes its objective function and there is an improvement in efficiency which increases with parameter $c$, the marginal cost of the public firm. The change in the objective function of this firm and the improvement in efficiency affect the output level of industry and, thus, the consumer and producer surplus and environmental damage. Therefore, to explain the decision taken by the government a comparison must be made between the consumer surplus, the producer surplus and environmental damage in the private and mixed duopolies.

\footnotetext{
8 It can be shown that, if the public firm is more inefficient abating pollution than the private firm or if the emissions per unit of output of the public firm are greater than that of the private firm, the range of values of parameter $c$ for which the government privatizes the public firm is greater than in proposition 2. Moreover, it is easy to see that if we assume that the government chooses an environmental tax instead of an environmental standard the result shown in this proposition holds.
} 
In zone I, as the public firm maximizes social welfare and its inefficiency is low enough, $C S^{M}$ is greater enough than $C S^{P}$. Thus, the government does not privatize it since, although in the mixed duopoly $E D^{M}$ is greater than $E D^{P}$ (since $e^{M>e^{P}}$ ) and $P S^{M}$ is lower than $P S^{P}$, $C S^{M}$ is sufficiently greater than $C S^{P}$.

The decision taken by the government in zone II is explained by the following effects. First, as we have seen in proposition $1, E D^{M}$ is greater than $E D^{P}$ and $P S^{M}$ is lower than $P S^{P}$. Second, in this zone, as $C S^{M}$ decreases with $c, C S^{M}$ is lower in zone II than in zone I; as a result, the difference between $C S^{M}$ and $C S^{P}$ is low enough. Therefore, the government privatizes the public firm.

The decision taken by the government in zone III is explained by three effects. First, as we have seen in lemma 3, $P S^{M}$ is lower than $P S^{P}$ and $P S^{M}$ decreases with $c$. Second, as we have seen in proposition $1, E D^{M}$ is lower than $E D^{P}$. Third, since $C S^{M}$ decreases with $c$, the consumer surplus is lower in this zone than in other zones; thus, the difference between $C S^{M}$ and $C S^{P}$ is lower than in zone II. Given that parameter $c$ is sufficienlty greater the first effect dominates, and the government privatizes the public firm.

In this section we have analyzed the decision whether to privatize when the government chooses an environmental standard to protect the environment. In the following section, we shall analyze the case in which the social welfare function does not take in environmental damage and the government does not set an environmental standard (we denote this case as the benchmark case). We shall then compare the results obtained in the benchmark case with those obtained in Section 3. 


\section{The decision whether to privatize in the benchmark case}

In this section we consider the same model as in Section 2, but with the following changes. First, the profit function of firm $i$ is given by expression (1), assuming that firms do not have to abate emissions since the government does not set an environmental standard (thus, $C A_{i}=0$ ). Secondly, the social welfare function considered by the government is given by expression (2), assuming that environmental damage is not considered in this function (thus, $E D=0$ ).

The timing of the game is now the following. In the first stage, the government decides whether to privatize the public firm or not. In the second stage, each firm chooses its output level. Solving this game we obtain the following results.

In the mixed duopoly, in equilibrium, the output levels of the firms, the profit of the firms, the consumer surplus and social welfare are, respectively:

$$
q_{0}^{M}=A-2 c, q_{1}^{M}=c, \pi_{0}^{M}=0, \pi_{1}^{M}=c^{2}, C S^{M}=\frac{(A-c)^{2}}{2}, W^{M}=\frac{(A-c)^{2}}{2}+c^{2}
$$

In the private duopoly, in equilibrium, the output levels of the firms, the profit of the firms, the consumer surplus and social welfare are, respectively:

$$
q_{0}^{P}=q_{1}^{P}=\frac{A}{3}, \pi_{0}^{P}=\pi_{1}^{P}=\frac{A^{2}}{9}, C S^{P}=\frac{2 A^{2}}{9}, W^{P}=\frac{4 A^{2}}{9} .
$$

By comparing the results obtained in the mixed and private duopolies we obtain the following result. 
Lemma 4. In equilibrium, the government privatizes the public firm if $c_{\gamma} \leq c<\bar{c}$; the government prefers a mixed duopoly if $0<c<c_{\gamma}$, where $c_{\gamma}=\frac{A(3-\sqrt{6})}{9}$.

This lemma shows that if parameter $c$ is high enough $\left(c_{\gamma} \leq c<\bar{c}\right)$, the government privatizes the public firm. However, if parameter $c$ is low enough $\left(0<c<c_{\gamma}\right)$, the government prefers a mixed duopoly. As usual, $C S^{M}$ is greater than $C S^{P}$ but $P S^{M}$ is lower than $P S^{P}$. If $0<c<c_{\gamma}$ the government does not privatize the public firm since, as that firm maximizes social welfare and its inefficiency is low enough, $C S^{M}$ is greater enough than $C S^{P}$, which offsets the lower producer surplus. If $c_{\gamma} \leq c<\bar{c}$ the government privatizes the public firm and, thus, there is an improvement in efficiency, the producer surplus increases and the consumer surplus decreases. Given that the inefficiency of the public firm is high enough, the increase in the producer surplus has a greater weight than the decrease in the consumer surplus in social welfare.

Next we shall compare proposition 2 with lemma 4 to analyze whether the results obtained in the benchmark case change when we assume that the government sets an environmental standard and that the social welfare function also takes in environmental damage caused by firms. We denote this last case as the environmental policy case.

Proposition 3. If $0<c<c_{\beta}$ both in the benchmark case and in the environmental policy case the government prefers the mixed duopoly (zone $\left.I^{\prime}\right)$. If $c_{\beta} \leq c<c_{\gamma}$ in the first case the government prefers the mixed duopoly but in the second case the government privatizes the public firm (zone II'). Lately, if $c_{\gamma} \leq c<\bar{c}$ in both cases the government privatizes the public firm (zone III'). 
In zone $I^{\prime}$ the government does not privatize the public firm in both cases since, the inefficiency of this firm is low enough and, thus, the consumer surplus has a greater weight than the producer surplus in social welfare. In fact, in the environmental policy case, although $E D^{M}$ is greater than $E D^{P}$, the consumer surplus has a greater weight than the producer surplus and environmental damage in social welfare.

In zone III' the government privatizes the public firm in both cases since, the inefficiency of this firm is high enough and, thus, producer surplus has a greater weight than consumer surplus in social welfare. In fact, in the environmental policy case, although $E D^{M}$ is lower than $E D^{P}$, the producer surplus has a greater weight in social welfare than the consumer surplus and environmental damage.

In zone $\mathrm{II}^{\prime}$, as seen in proposition 2 , in the environmental policy case the government privatizes the public firm. However, as seen in lemma 4, in the benchmark case the government prefers the mixed duopoly. In this second case there is no upper limit on emissions and, as firms do not have to pay to abate pollution emissions, the output of industry is greater than in the first case (both in the mixed and private duopolies). Thus, the consumer surplus has a greater weight in social welfare in the benchmark case than in the environmental policy case. Moreover, since the public firm maximizes social welfare, the output of industry and the consumer surplus are greater in the mixed duopoly than in the private duopoly. Therefore, in the benchmark case, the government prefers the mixed duopoly since, $C S^{M}$ is greater than $C S^{P}$ which offsets the fact that $P S^{M}$ is lower than $P S^{P}$. It must be noted that, in the benchmark case, the social welfare function does not take in environmental damage.

Now that we have analyzed the decision by the government whether to privatize the public firm when there is one private firm and one public firm, the next step is to analyze whether 
the results of the model change when we consider that the competition in the product market increases.

\section{5. $N$ private firms}

In this section we extend the model of section 2 by assuming that there are $n$ private firms $(n \geq 2)$ instead of one, and one public firm that can be privatized. We also assume that the marginal cost of the private firms is zero and that the marginal cost of the public firm is $c<\overline{c_{n}}=\frac{A}{2(1+n)}$.

First we consider the environmental policy case. By comparing the results obtained in the mixed and private oligopolies (see Appendix) we obtain the following result.

Proposition 4. In the environmental policy case, in equilibrium, we have that:

i) If $n=2$ the public firm is privatized when $c_{\beta n} \leq c<\overline{c_{n}}$; the government prefers a mixed duopoly when $c<c_{\beta n} \cdot{ }^{9}$

ii) If $n \geq 3$ the government always privatizes the public firm.

In order to explain the result obtained in proposition 4, we have to analyze how the consumer surplus, the producer surplus and the environmental damage change when the number of private firms increases, in both the private and mixed oligopolies.

When $n$ increases, the output of industry increases in both the private and mixed oligopolies, but more strongly in the former. The explanation of this result is the following. We have seen in proposition 1 that when $n=1$, given that the public firm maximizes social

9 The value of $c_{\beta n}$ is shown in the appendix. 
welfare, the output of industry in the mixed duopoly is greater than in the private duopoly. When $n$ increases, competition in the private oligopoly increases more than in the mixed oligopoly and, thus, the output of industry increases strongly in the former case. As a result, when $n$ increases $C S^{P}$ increases more than $C S^{M}$. But it must be noted that, independently of the number of private firms, $C S^{M}$ is greater than $C S^{P}$.

When $n$ increases, given that competition in the product market increases more in the private oligopoly than in the mixed oligopoly, $P S^{P}$ decreases more than $P S^{M}$. But it must be noted that, independently of the number of private firms, $P S^{M}$ is lower than $P S^{P}$.

As a result of the above, when $n$ increases, $C S^{P}+P S^{P}$ increases more than $C S^{M}+P S^{M}$; thus, when $n$ is great enough $(n \geq 3), E D^{P}$ is greater than $E D^{M}$. When $n$ is low enough $(n=2)$, as shown in proposition 1 for $n=1$, the $E D^{P}$ can be greater or lower than $E D^{M}$.

Now that we have compared the consumer surplus, the producer surplus and the environmental damage in the mixed and private oligopolies, we shall explain the decision by the government whether to privatize. Proposition 4 shows that when $n$ is low enough $(n=2)$ the result of proposition 3 holds. This last proposition analyzes whether the government privatizes the public firm or not when $n=1$. The result obtained for $n=2$ is the same than for $n=1$ since the number of private firms is low enough and, thus, the same effects arise in both cases. However, it must be noted that, when $n=2$, the range of values of parameter $c$ for which the government prefers a mixed oligopoly is lower than when $n=1$; the reason is that, when $n$ increases, $C S^{P}$ increases more than $C S^{M}$. When $n$ is high enough $(n \geq 3)$, the difference between $C S^{M}$ and $C S^{P}$ is low. Thus, although $E D^{P}$ is greater than $E D^{M}$, as $P S^{P}$ is great enough than $P S^{M}$ the government always privatizes the public firm. 
Next we consider the benchmark case when there are $n$ private firms. By comparing the results in mixed and private oligopolies (see Appendix) we obtain the following result.

Lemma 5. In equilibrium, in the benchmark case, the government privatizes the public firm if $c_{m} \leq c<\overline{c_{n}}$. However, the government prefers a mixed duopoly if $c<c_{\gamma_{n}}$, where $c_{\gamma n}=\frac{A\left(2+n-\sqrt{3+2 n+n^{2}}\right)}{(2+n)(1+2 n)}$.

Lemma 5 points out that the main result shown in lemma 4 does not change with $n$. However, it must be noted that, when $n$ increases, the range of values of parameter $c$ such that the government prefers a mixed oligopoly decreases $\left(\partial c_{\gamma n} / \partial n<0\right)$. The reason is that when $n$ increases, the difference between $C S^{M}$ and $C S^{P}$ decreases, as does the difference between $P S^{P}$ and $P S^{M}$. The first effect has a greater weight than the second and, thus, when $n$ increases, the range of values of parameter $c$ such that the government prefers a mixed oligopoly is lower than in lemma 4.

By comparing proposition 4 and lemma 5 the following result is obtained.

Proposition 5. In equilibrium, we have that:

i) When $n=2$, if $0<c<c_{\beta n}$ both in the benchmark case and in the environmental policy case the government prefers the mixed oligopoly. If $c_{\beta n} \leq c<c_{\eta n}$ in the first case the government prefers the mixed oligopoly but in the second case the government privatizes the public firm. Lastly, if $c_{\gamma_{n}} \leq c<\overline{c_{n}}$ the government privatizes the public firm in both cases.

ii) When $n \geq 3$, the government privatizes the public firm in the benchmark case only if $c_{\gamma_{n}} \leq c<\overline{c_{n}}$, while the government always privatizes the public firm in the environmental policy case. 
The explanation of the first case of proposition 5, given that the number of private firms is low enough, is similar to that of proposition 3.

When $n \geq 3$, in the benchmark case the public firm is privatized only when parameter $c$ is great enough since the producer surplus has more weight than the consumer surplus in social welfare. However, in the environmental policy case, the government always privatizes the public firm independently of the value of parameter $c$ since the standard chosen by the government affects the consumer and producer surplus. This result can be explained by considering the following three effects. First, the consumer surplus is lower in the environmental policy case than in the benchmark case (in both the mixed and private oligopolies). Second, the producer surplus is greater in the environmental policy case than in the benchmark case (in both the mixed and private oligopolies). Third, $E D^{P}$ is greater than $E D^{M}$ in the environmental policy case. The second effect dominates the first and the third effects and, thus, in the environmental policy case, the government always privatizes the public firm. In the benchmark case, there are only two effects since the social welfare function does not take in environmental damage. The second effect dominates the first only if parameter $c$ is high enough; in this case, the government privatizes the public firm.

\section{Conclusions}

The literature on mixed oligopoly that analyzes the decision by the government whether to privatize a public firm does not assume explicitly that firms pollute the environment and, thus, the environmental policy of the government is not taken into account. On the other hand, the literature on the environment analyzes the environmental policy of the government but does not consider that there are public firms competing with private firms in the product market. We fill this gap in literature by analyzing the decision by the government whether to privatize a public firm when it chooses an environmental standard to control pollution. In 
order to carry out this analysis, we assume that there are $n$ private firms and one public firm that pollute the environment and that, the public firm is less efficient than the private firms.

We show that, when the number of private firms is low enough $(n \in\{1,2\})$, the government privatizes the public firm if it is inefficient enough; this inefficiency depends on the marginal cost of the public firm, on market size, and on the valuation of the environment by the government. When the number of private firms is high enough $(n \geq 3)$ the government always privatizes the public firm. We also show that the range of values of the parameters for which the government privatizes the public firm is greater than in the benchmark case.

The result of the model does not depend on whether the government uses an environmental standard as its environmental policy tool. If the government uses an environmental tax instead of an environmental standard the main result of the model holds.

\section{Acknowledgements}

We would like to thank A. Beitia, F. J. Casado- Izaga and A. Saracho for helpful comments. Financial support from UPV (HB-8238/2000) and DGES (BEC 2000-0301) is gratefully acknowledged. 


\section{Appendix}

\section{A.1. The environmental policy case}

We consider first that there are $n$ private firms and one public firm. In the mixed oligopoly, in equilibrium, the environmental standard, the outputs of the firms, the profits of the firms, environmental damage, the consumer surplus and social welfare are, respectively:

$$
\begin{aligned}
e^{M} & =\frac{A\left(8+7 n+n^{2}\right)-c(8+n)}{\left(8+17 n+8 n^{2}+n^{3}\right)+d\left(4+5 n+n^{2}\right)^{2}} \\
q_{0}^{M} & =\frac{2 A\left(4+5 n+n^{2}\right)(1+d+d n)-c\left(8+9 n+6 n^{2}+n^{3}+d\left(8+6 n+n^{2}\right)(1+n)^{2}\right)}{8+17 n+8 n^{2}+n^{3}+d\left(4+5 n+n^{2}\right)^{2}}, \\
q_{i}^{M} & =\frac{(4+n)\left(A(1+n)(1+d+d n)+c\left(n+d(1+n)^{2}\right)\right)}{8+17 n+8 n^{2}+n^{3}+d\left(4+5 n+n^{2}\right)^{2}}, i=1, \ldots, n, \\
\pi_{0}^{M} & =\left(A-q_{0}^{M}-n q_{i}^{M}-c\right) q_{0}^{M}-\frac{1}{2}\left(q_{0}^{M}-e^{M}\right)^{2}, \\
\pi_{i}^{M} & =\left(A-q_{0}^{M}-n q_{i}^{M}\right) q_{i}^{M}-\frac{1}{2}\left(q_{i}^{M}-e^{M}\right)^{2}, i=1, \ldots, n,
\end{aligned}
$$

where $e^{M}, q_{0}^{M}$ and $q_{i}^{M}$ are given by (A1), (A2), and (A3) respectively.

$$
\begin{aligned}
& E D^{M}=\frac{(1+n)^{2}\left(A\left(8+7 n+n^{2}\right)-c(8+n)\right)^{2}}{2\left(8+17 n+8 n^{2}+n^{3}+d\left(4+5 n+n^{2}\right)^{2}\right)^{2}} \\
& C S^{M}=\frac{\left(A\left(8+14 n+7 n^{2}+n^{3}\right)(1+d+d n)-c\left(8+9 n+2 n^{2}+2 d(4+n)(1+n)^{2}\right)\right)^{2}}{2\left(8+17 n+8 n^{2}+n^{3}+d\left(4+5 n+n^{2}\right)^{2}\right)^{2}},
\end{aligned}
$$

$W^{M}=C S^{M}+\pi_{0}^{M}+n \pi_{i}^{M}-E D^{M}$, where $C S^{M}, \pi_{0}^{M}, \pi_{i}^{M}$ and $E D^{M}$ are given by (A7), (A4), (A5) and (A6) respectively.

Next we consider that the public firm is privatized and, thus, there are $n+1$ private firms. In the private oligopoly, in equilibrium, the environmental standard, the outputs of the firms, 
the profits of the firms, environmental damage, the consumer surplus and social welfare are, respectively:

$$
\begin{aligned}
& e^{P}=\frac{A(4+n)}{5+5 n+n^{2}+d(1+n)(3+n)^{2}}, q_{i}^{P}=\frac{A(3+n)(1+d+d n)}{5+5 n+n^{2}+d(1+n)(3+n)^{2}}, i=0, \ldots, n, \\
& \pi_{i}^{P}=\frac{A^{2}\left(11+10 n+2 n^{2}+6 d(1+n)(3+n)^{2}+3 d^{2}\left(3+4 n+n^{2}\right)^{2}\right)}{2\left(5+5 n+n^{2}+d(1+n)(3+n)^{2}\right)^{2}}, i=0, \ldots, n, \\
& E D^{P}=\frac{A^{2} d(4+n)^{2}(1+n)^{2}}{2\left(5+5 n+n^{2}+d(1+n)(3+n)^{2}\right)^{2}}, C S^{P}=\frac{A^{2}(3+n)^{2}(1+d+d n)^{2}(1+n)^{2}}{2\left(5+5 n+n^{2}+d(1+n)(3+n)^{2}\right)^{2}}, \\
& W^{P}=\frac{A^{2}(4+n)(1+d+d n)(1+n)}{2\left(5+5 n+n^{2}+d(1+n)(3+n)^{2}\right)} .
\end{aligned}
$$

It can be shown that $W^{P}=W^{M}$ for $c=c_{\beta n}$, where:

$$
\begin{aligned}
& c_{\beta n}=\left(A ( 1 + d + d n ) \left(40+85 n+58 n^{2}+14 n^{3}+n^{4}+d(8+n)\left(3+4 n+n^{2}\right)^{2}-\right.\right. \\
& \left(32+46 n+16 n^{2}+2 n^{3}\right)^{1 / 2}\left(40+125 n+133 n^{2}+62 n^{3}+13 n^{4}+n^{5}+\right. \\
& \left.\left.d\left(152+553 n+764 n^{2}+511 n^{3}+176 n^{4}+30 n^{5}+2 n^{6}\right)+d^{2}(1+n)^{3}\left(12+7 n+n^{2}\right)^{2}\right)^{1 / 2}\right) / \\
& \left(40+85 n+88 n^{2}+49 n^{3}+12 n^{4}+n^{5}+2 d\left(56+178 n+246 n^{2}+184 n^{3}+\right.\right. \\
& \left.\left.73 n^{4}+14 n^{5}+n^{6}\right)+d^{2}(1+n)^{3}(3+n)^{2}\left(8+7 n+n^{2}\right)\right) .
\end{aligned}
$$

\section{A.2. The benchmark case}

It is easy to see that, in the mixed oligopoly, in equilibrium, the outputs of the firms, the profits of the firms, the consumer surplus and social welfare are, respectively:

$$
q_{0}^{M}=A-c(1+n), q_{i}^{M}=c, \pi_{0}^{M}=0, \pi_{i}^{M}=c^{2}, i=1, \ldots, n,
$$




$$
C S^{M}=\frac{(A-c)^{2}}{2}, W^{M}=\frac{(A-c)^{2}}{2}+n c^{2} .
$$

It is easy to see that, in the private oligopoly, in equilibrium, the outputs of the firms, the profits of the firms, the consumer surplus and social welfare are, respectively:

$$
q_{i}^{P}=\frac{A}{2+n}, \pi_{i}^{P}=\frac{A^{2}}{(2+n)^{2}}, C S^{P}=\frac{A^{2}(n+1)^{2}}{2(2+n)^{2}}, W^{P}=\frac{A^{2}(1+n)(3+n)}{2(2+n)^{2}}, i=0, \ldots, n .
$$




\section{References}

Barrett S., 1994. Strategic environmental policy and international trade. Journal of Public Economics 54, 325-338.

Barros, F., 1995. Incentive schemes as strategic variables: An application to a mixed duopoly. International Journal of Industrial Organization 13, 373-386.

De Fraja, G., Delbono, F., 1989. Alternatives strategies of a public enterprise in oligopoly. Oxford Economic Papers 41, 302-311.

De Fraja, G., Delbono, F., 1990. Game theoretic models of mixed oligopoly. Journal of Economic Surveys 4, 1-17.

Estrin, S., de Meza, D., 1995. Unnatural monopoly. Journal of Public Economics 57, 471488.

Falk, I., Mendelson, R., 1993. The economics of controlling stock pollutants: An efficient strategy for greenhouse gases. Journal of Environmental Economics and Management 25, $75-88$.

Kikeri, S., Nellis, J., Shirley, M., 1992. Privatization: The lessons of experience. Washington, DC: The World Bank.

Markusen, J.R., Morey, E. R., Olewiler, N., 1995. Competition in regional environmental policies when plant locations are endogenous. Journal of Public Economics 56, 55-77.

Markusen, J.R., 1997. Costly pollution abatement, competitiveness and plant location decisions. Resource and Energy Economics 19, 299-320.

Matsumura, T., 1998. Partial privatization in mixed duopoly. Journal of Public Economics 70, 473-483.

Megginson, W.L., Nash, R.C., van Randenborg, M., 1994. The financial and operating performance of newly privatized firms: An international empirical analysis. Journal of Finance 49, 403-452.

Mueller, D. C., 1989. Public choice II. Cambridge, UK: Cambridge University Press.

Pal, D., 1998. Endogenous timing in a mixed oligopoly. Economic Letters 61, 181-185. 
Ulph, A., 1996. Environmental policy and international trade when governments and producers act strategically. Journal of Environmental Economics and Management 30, 265-281.

van der Ploeg, F., de Zeeuw, A.J., 1992. International aspects of pollution control. Environmental and Resource Economics 2, 117-139.

Vining, A., Boardman, A., 1992. Ownership vs. competition: efficiency in public enterprise. Public Choice 73, 205-239. 